\title{
Feasibility and construct validity of a novel laparoscopic skills testing and training model
}

\author{
Carlos Roger Molinas • Gunter De Win • \\ Ortrun Ritter • Joerg Keckstein • Marc Miserez • \\ Rudi Campo
}

Received: 14 January 2008 / Accepted: 28 March 2008 / Published online: 6 May 2008

(C) Springer-Verlag 2008

\begin{abstract}
The apprentice-tutor model was useful for training surgeons for many years, but the complexity of surgical technology in the 21 st century, especially endoscopic surgery, has exponentially increased the demands for surgical education. Therefore, more and more people now accept that endoscopic surgery, demanding as it requires specific skills, should also be taught outside the operating theatre. Although many systems, including animal models and simulators, have been proposed, an in-house structured and validated method for testing and training laparoscopic skills is missing in gynaecology. We have developed a laparoscopic skills testing and training (LASTT) model and performed two studies evaluating its feasibility and the construct validity of three different exercises (camera navigation, camera navigation and forceps handling, and forceps handling and bi-manual coordination), specifically selected to test and train laparoscopic psychomotor skills
\end{abstract}

C. R. Molinas · J. Keckstein · R. Campo

European Academy of Gynaecological Surgery,

Leuven, Belgium

C. R. Molinas

Centre for Gynaecological Endoscopy, Centro Médico La Costa,

Asunción, Paraguay

G. De Win · M. Miserez

Centre for Surgical Technologies, Katholieke Universiteit Leuven, Leuven, Belgium

O. Ritter $\cdot$ J. Keckstein

ENDOVISION European School of Endoscopy,

Villach, Austria

R. Campo ( $\square)$

Leuven Institute for Fertility and Embryology,

Leuven, Belgium

e-mail: rudi.campo@lifeleuven.be
(LPS). In the first study, ten experts and 14 novices repeated each exercise between 20 and 30 times. The results demonstrated that the model is useful for testing and training laparoscopic skills. Clear learning curves were observed for both experts and novices, with better scores for the former at the beginning and the end of the study, proving the construct validity of the model. In the second study, 42 experts and 241 novices repeated each exercise three times during skill evaluation workshops organised by the European Academy of Gynaecological Surgery. The results confirmed the construct validity of the model. In conclusion, the LASTT model seems a cost-effective tool for providing an in-house program for continuous training and evaluation of LPS in all surgical disciplines in which laparoscopic procedures are, or might be, performed.

Keywords Laparoscopy · Skills · Testing · Training · Model $\cdot$ Construct validity

\section{Introduction}

In addition to the typical surgical skills (SS) required for open surgery (i.e. manual dexterity and knowledge of anatomy, pathology and surgical techniques), laparoscopic surgery demands specific laparoscopic psychomotor skills (LPS) (i.e. laparoscopic camera navigation, depth appreciation from a two-dimensional screen using subtle visual clues, hand-eye coordination, remote handling of instruments without tactile feedback, fine motor skills to deal with the fulcrum effect and the lever forces of the long instruments).

The effective acquisition of these skills can only be achieved by appropriate training. The apprentice-tutor model has been used for many years as the paradigm for training in surgery. In this model the apprentice first 
observes, then helps and finally imitates the actions of a skilled tutor in the operating room. However, the restricted number of tutors available and the long learning curves reported (i.e. large numbers of procedures to reach proficiency) [1-6] makes this model not suitable anymore as the sole system for training in surgery. This is especially relevant for gynaecological laparoscopic surgery, because gynaecologists in training are exposed to very limited numbers of surgical cases in routine practice.

Owing to the limitations of the apprentice-tutor model, more and more specialists now agree that training has also to be done outside the operating room. Therefore, many animal [7-16] and inanimate [17-35] models have been proposed. Animal models seem ideal because they simulate the clinical scenario, but, due to financial and ethical restrictions, they are not widely and routinely used. Inanimate models (e.g. trainer box, virtual reality) allow relaxed and controlled training, and learning curves for different laparoscopic tasks have been reported [27, 36-39]. Trainer boxes are relatively cheap and accessible [20], whereas virtual reality models provide an objective evaluation of the learning process [37], both being equally effective for the acquisition of laparoscopic skills [21].

In contrast with animal models that are normally used for short periods (e.g. 2-3 day courses), inanimate models have the advantage of allowing training for longer periods, which is crucial to ensure full LPS acquisition and not only exposure to specific laparoscopic tasks.

In spite of the exciting data available for the testing and training of laparoscopic skills [31-34, 40-48], structured and validated training programmes to enable the individual to acquire LPS before starting traditional training in the operating room are not implemented in most places. The ideal model should be, as well as being feasible, also well validated. Validity is the capacity of a method actually to teach or measure what it is intended to teach or measure, and different types of validity have been described. Face validity indicates the realism of the method; content validity indicates the appropriateness of the method as a teaching modality; construct validity indicates the capacity of the method to distinguish the experienced surgeon from the inexperienced surgeon, whereas criterion validity compares the results of the new method with those of older techniques. The two types of criterion validity are concurrent validity, which indicates the extent to which the method correlates with the "gold standard", and predictive validity, which indicates the extent to which the method predicts future performance [18].

We have developed a structured laparoscopic skills testing and training (LASTT) model that can be used as an insert in any trainer box for both testing and training LPS, and we carried out two consecutive studies for evaluating its feasibility and its construct validity.

\section{Materials and methods}

Participants and venue

A pilot study (Study 1) was performed by students, gynaecologists without or with little experience in laparoscopy, and gynaecologists with proven experience in this discipline $(n=24)$ who were recruited specifically to meet the objectives of this study. The study was carried out in 2005 at the Centre for Surgical Technologies of the Katholieke Universiteit Leuven (Leuven, Belgium) and at the ENDOVISION European School of Endoscopy (Villach, Austria).

A second study (Study 2) was performed by residents and certified gynaecologists with different levels of experience in laparoscopic surgery $(n=283)$ who voluntarily attended the skills evaluation workshops organised by the European Academy of Gynaecological Surgery (EAGS) during the following meetings: workshop at the Leuven Institute for Fertility and Embryology (LIFE) in Leuven, Belgium in $2005(n=17)$, 19th European Congress on Obstetrics and Gynaecology (EBCOG) in Torino, Italy in $2006(n=44), 1$ st Congress on Gynaecology and Obstetrics MERCOSUR 2006 in Asunción, Paraguay in $2006(n=$ 158), 3rd Portuguese Congress of Reproductive Medicine in Porto, Portugal in $2007(n=36)$ and advance course on Gynaecological Laparoscopic Surgery at the Institute de Recherche contre les Cancers de l'Appareil Digestif/ European Institution of TeleSurgery (IRCAD/EITS) in Strasbourg, France in 2007 ( $n=28)$. Participants came from 34 countries in Europe, Asia, Africa, North America and Latin America and were enrolled for the study after filling in a pre-designed questionnaire.

All participants who met the inclusion criteria determined in the experimental design were included, and their age, gender, training status [i.e. students, residents or specialists in obstetrics and gynaecology (OB\&GYN)], dominant hand $(\mathrm{DH})$ and non-dominant hand (NDH) were recorded.

Instruments and materials

The pilot version of the studies was conducted using a specially designed inanimate three-dimensional model, the laparoscopic skills testing and training (LASTT) model, suitable for performing a series of laparoscopic exercises simulating all possible laparoscopic movements in the pelvis. This model is made up of a horizontal platform $(16.5 \mathrm{~cm} \times 30 \mathrm{~cm})$ with two modules in the back, two modules in the middle and two modules in the front. Different inserts can be placed in each of the modules as well as the platform for each of the different exercises.

The LASTT model was inserted into the Szabo trainer box (Karl Storz, Tutlingen, Germany), mounted with the 
relevant materials for each of the different exercises and connected to either a conventional or an all-in-one (monitor, light source and video-camera) laparoscopic tower (Telepack, Karl Storz) (Fig. 1). The exercises were performed with standard laparoscopic instruments: $10 \mathrm{~mm}$ $0^{\circ}$ optic, $10 \mathrm{~mm} 30^{\circ}$ optic, $5 \mathrm{~mm}$ Kelly dissection forceps and $5 \mathrm{~mm}$ Matkowitz grasping forceps (Karl Storz).

\section{Laparoscopic exercises}

\section{Exercise 1 (E1): laparoscopic camera navigation}

This exercise was used to evaluate the participants' ability to navigate a laparoscopic camera with a $30^{\circ}$ optic. This was done by measuring their ability to identify 14 different targets placed at different sites in the LASTT model. The targets were mounted on the different modules in such a way that they could only be identified by moving the laparoscope in all directions (rotation, lateral and zoom-in/ out movements). Each target included a large symbol only identifiable from a panoramic view and a small symbol only identifiable from a close-up view (Fig. 2a). The participant stood behind the trainer box in the midline. The optic was introduced through a midline port, the camera being held with one hand and the fibre optic cable with the other for lateral, zoom-in/out and rotation movements. The individual started the exercise by identifying the large symbol on the first target (i.e. 1) and then the small symbol situated next to it, which indicated the next large symbol to be identified. Following this order, the participant continued till the small symbol on the last target (i.e. end) had been identified. The types of symbols and the places where they were mounted varied for each repetition. The time required for the participant to identify the 14 targets was recorded.

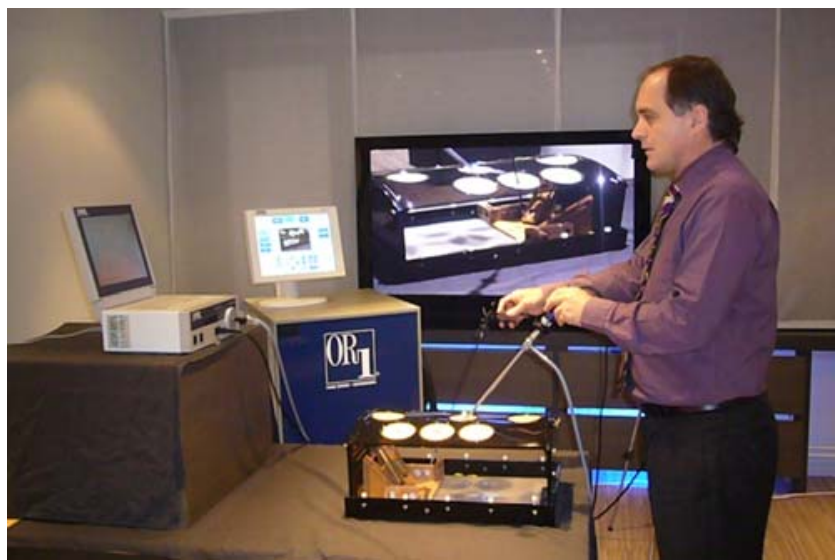

Fig. 1 The laparoscopic skills testing and training (LASTT) model mounted in the Szabo trainer box and connected to the all-in-one laparoscopic tower (Telepack) at the Academy

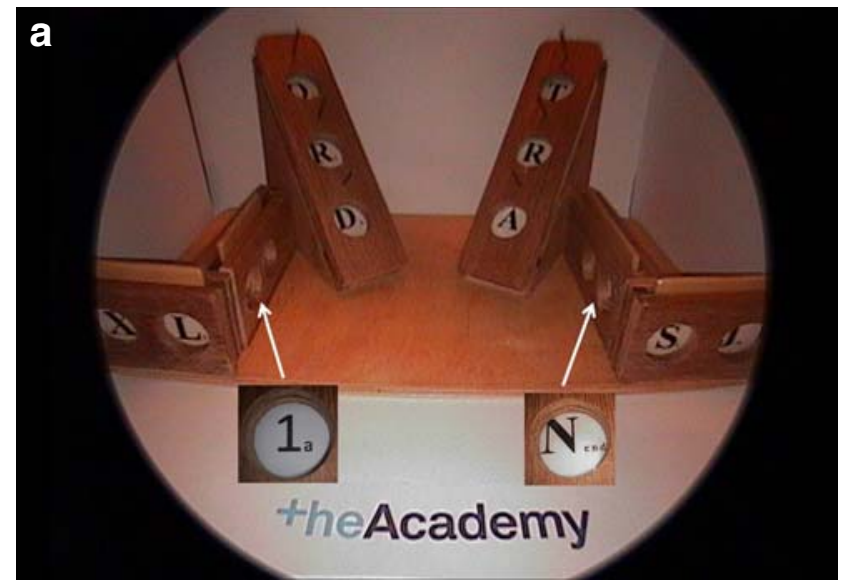

b

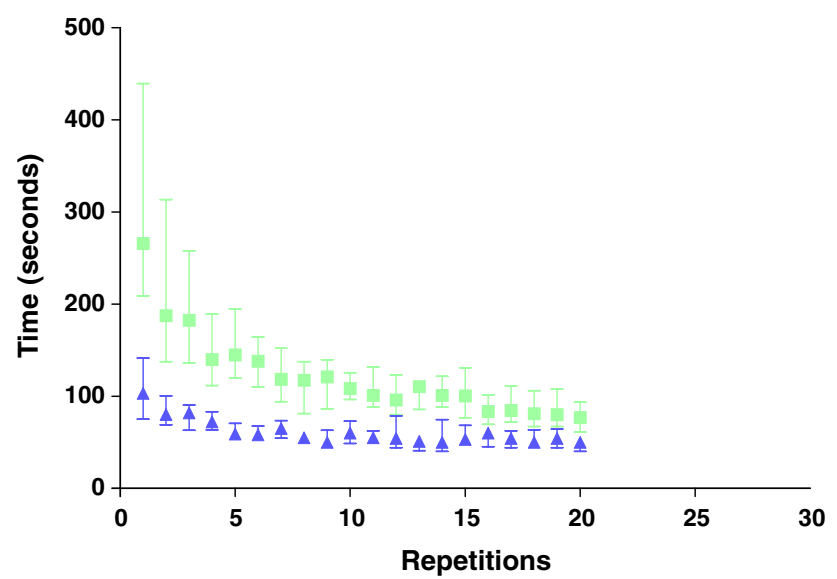

C

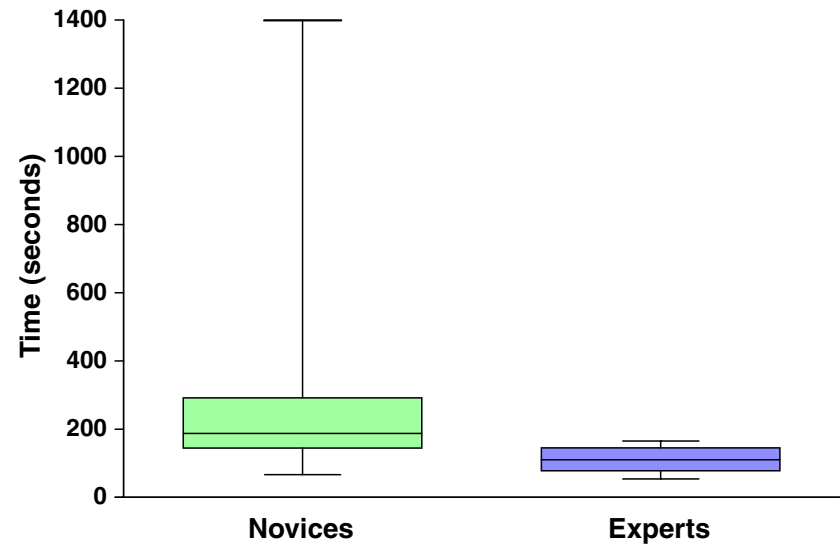

Fig. 2 Exercise 1 (laparoscopic camera navigation). The participants' ability to navigate a laparoscopic camera with a $30^{\circ}$ optic was evaluated by measuring their ability to identify 14 different targets placed at different sites in the LASTT model (a). The time required for each participant to identify all targets was recorded. In Study 1 (b), participants specifically recruited for the study performed 20 consecutive repetitions so that the learning curves and the construct validity could be evaluated. Participants were classified as novices (green symbols) or experts (blue symbols). Median values (interquartile range) of each repetition are presented. In Study 2 (c), large-scale testing was conducted during skill evaluation workshops at international gynaecological meetings so that the construct validity could be evaluated. Median values (minimum, interquartile range, maximum) of triplicate observations are presented 
Fig. 3 Exercise 2 (laparoscopic camera navigation and laparoscopic forceps handling). The participants' ability to navigate a laparoscopic camera with a $0^{\circ}$ optic with the $\mathrm{NDH}$ and to handle a laparoscopic forceps with the $\mathrm{DH}$ was evaluated by measuring their ability to grasp, transport, position and introduce pre-defined objects into pre-defined targets in the LASTT model (a). The numbers of objects transported in $2 \mathrm{~min}$ were recorded. In Study 1 (b), participants specifically recruited for the study performed 30 consecutive repetitions so that the learning curves and the construct validity could be evaluated. Participants were classified as novices (green symbols) or experts (blue symbols). Median values (interquartile range) of each repetition are presented. In Study 2 (c), large-scale testing was conducted during skill evaluation workshops at international gynaecological meetings so that the construct validity could be evaluated. Median values (minimum, interquartile range, maximum) of triplicate observations are presented

\section{Exercise 2 (E2): laparoscopic camera navigation and laparoscopic forceps handling}

This exercise was used to evaluate the participants' ability to navigate a laparoscopic camera with a $0^{\circ}$ optic with the $\mathrm{NDH}$ and to handle a laparoscopic forceps with the DH. This was done by measuring their ability to grasp, transport, position and introduce pre-defined objects into pre-defined targets in the LASTT model. Twelve coloured objects (cylinders of $5 \mathrm{~mm}$ length and $4 \mathrm{~mm}$ width with an opening of $2 \mathrm{~mm}$ from both sides) were placed in the centre of the horizontal platform, and six coloured targets (nails of $10 \mathrm{~mm}$ length and $1 \mathrm{~mm}$ width) were mounted on the LASTT model. The matched targets and objects were identifiable by colour (Fig. 3a). The participant stood behind the trainer box in the midline. The optic was introduced through a midline port and a Kelly forceps through a lower and lateral port, either to the right or to the left according to the DH side. The Kelly forceps was held with the $\mathrm{DH}$ and the camera with the NDH. The participant started the exercise by identifying the first target and an object of the same colour. Then, the object was grasped, transported, positioned and introduced into its target. Only when the participant had succeeded in introducing the first object into the first target, was he/she able to continue with the others in a fixed order. The numbers of objects successfully transported in 2 min were recorded.

\section{Exercise 3 (E3): laparoscopic forceps handling and bi-manual coordination}

This exercise was use to evaluate the participant's ability to handle laparoscopic forceps simultaneously with the DH and the NDH. This was done by measuring the participant's ability to grasp pre-defined objects with the $\mathrm{DH}$ and grasp them again with the NDH, transporting, positioning and introducing them into pre-defined targets on the LASTT model. Twelve objects (coloured push pins $10 \mathrm{~mm} \times 5 \mathrm{~mm}$ with a tail of $10 \mathrm{~mm}$ ) were placed in the centre of the

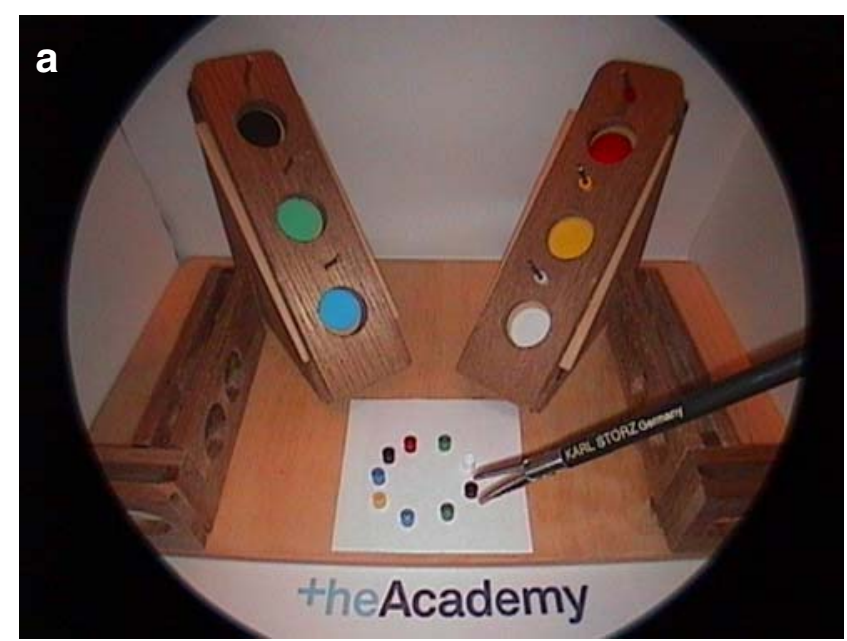

b

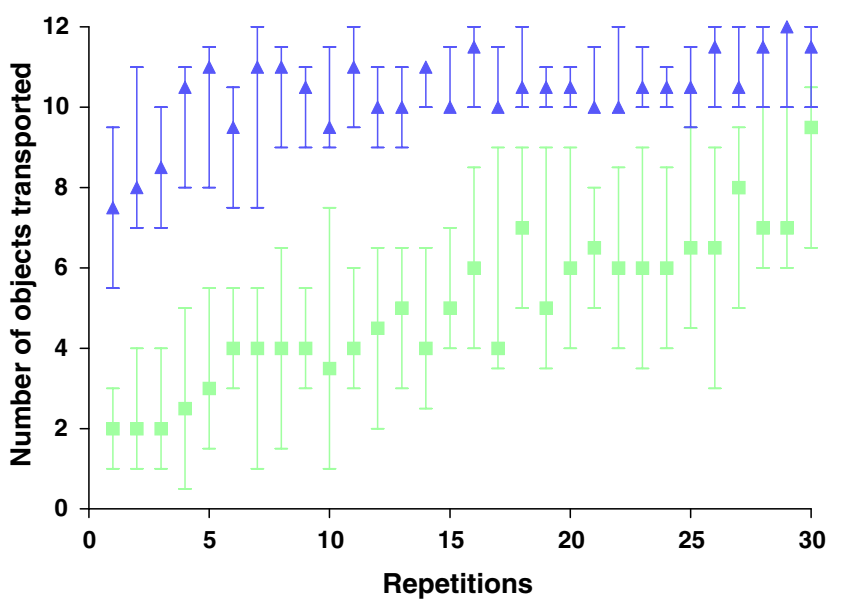

C

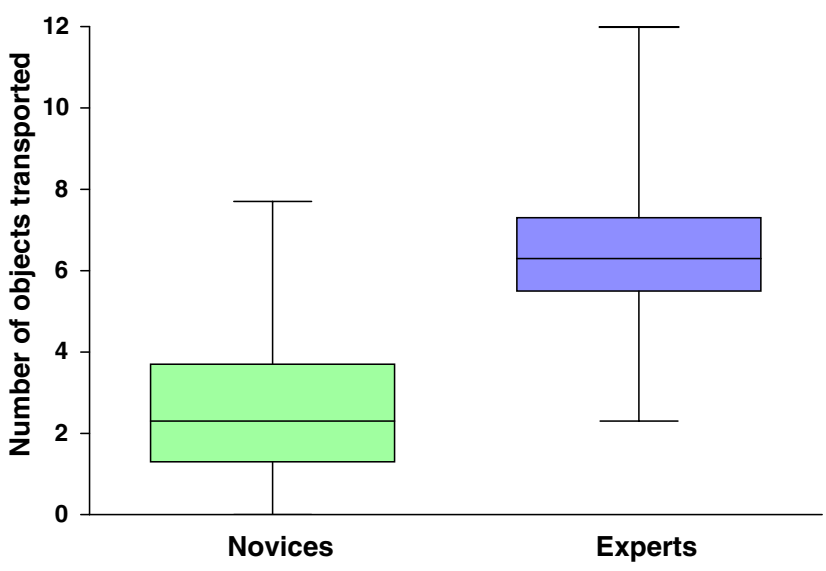

horizontal platform and six coloured targets (flat circular holes of $20 \mathrm{~mm}$ diameter) were mounted on the LASTT model. The matched targets and objects were identifiable by colour (Fig. 4a). A $0^{\circ}$ optic was introduced through a midline port, and a Kelly and a Matkowitz forceps were introduced through lower and lateral ports, either to the left or to the right according to the $\mathrm{DH}$. An assistant stood 
Fig. 4 Exercise 3 (laparoscopic forceps handling and bi-manual coordination). The participants' ability to handle laparoscopic forceps simultaneously with the $\mathrm{DH}$ and the $\mathrm{NDH}$ was evaluated by measuring their ability to grasp pre-defined objects with the DH and to grasp them again with the NDH and transport, position and introduce them into pre-defined targets in the LASTT model (a). In Study 1 (b), participants specifically recruited for the study performed 30 consecutive repetitions so that the learning curves and the construct validity could be evaluated. The time required for transporting six objects was recorded and median values (interquartile range) of each repetition are presented. Participants were classified as novices (green symbols) or experts (blue symbols). In Study 2 (c), large-scale testing was conducted during skill evaluation workshops at international gynaecological meetings so that the construct validity could be evaluated. The numbers of objects transported in 2 min were recorded, and median values (minimum, interquartile range, maximum) of triplicate observations are presented

behind the trainer box in the midline to hold and navigate the optic according to the instructions of the participant, who stood to the left of the trainer box and held the Matkowitz forceps with the DH and the Kelly forceps with the NDH. The participant started the exercise by identifying the first target and an object of the same colour. Then, the push pin was grasped by the head with the Matkowitz forceps (DH) and exposed to the Kelly forceps (NDH), with which it was re-grasped by the tail, transported, positioned and introduced into its target. Only when the participant had succeeded with the introduction of the first object into the first target, was he/she able to continue with the others. In Study 1 the time required for transporting six objects was recorded. In Study 2 the number of objects successfully transported in a fixed time $(2 \mathrm{~min})$ was recorded.

\section{Experimental design and statistics}

Participants were divided in two groups: novices and experts. As the expertise level of surgeons is based on the level and numbers of surgeries they are able to perform, and as a universal and standard classification system for gynaecological laparoscopic surgery does not exist, the classification of the European Society for Gynaecological Endoscopy (ESGE) was used in this study (Table 1). Participants were described as novices if they had not yet performed any laparoscopy or had performed basic procedures only (Table 1), regardless of the number of procedures already performed. Conversely, participants were described as experts if they had performed, in addition to any basic procedures, at least 30 intermediate and/or advanced procedures (Table 1). Participants who could not be allocated to one of the two groups were excluded from the study.

For Study $1 \quad(n=24)$, the level of all participants was ascertained by evaluation of their individual profiles before recruitment and only then were they included in the study and referred to as novices $(n=14)$ or experts $(n=10)$. For

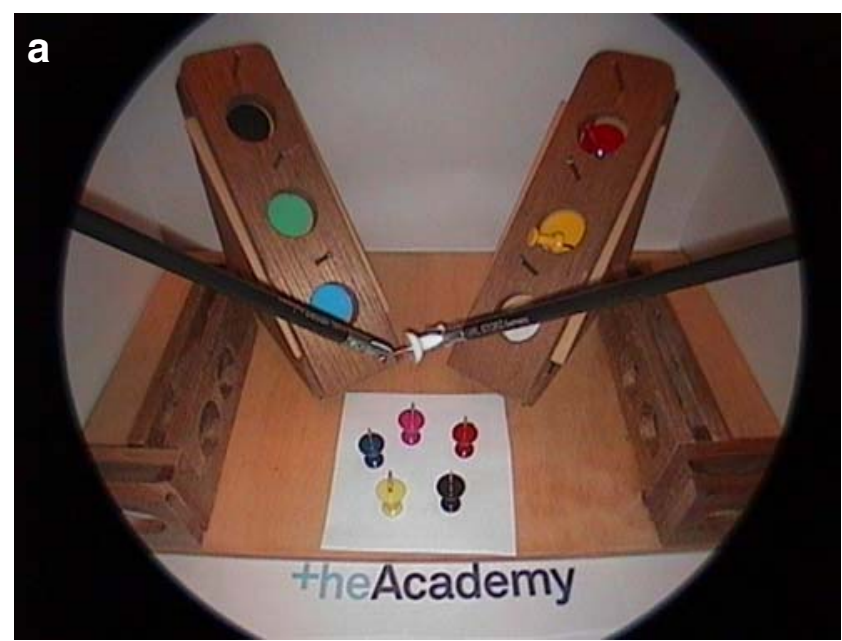

b

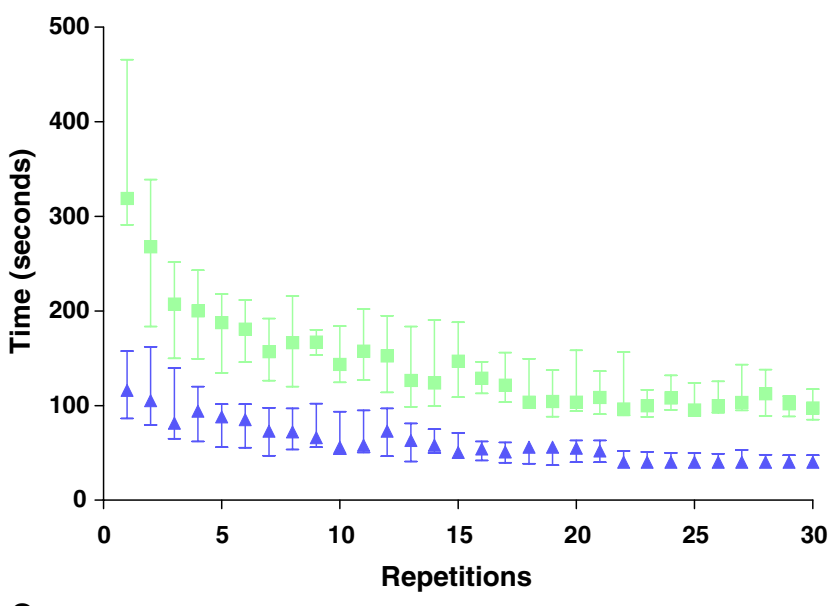

C

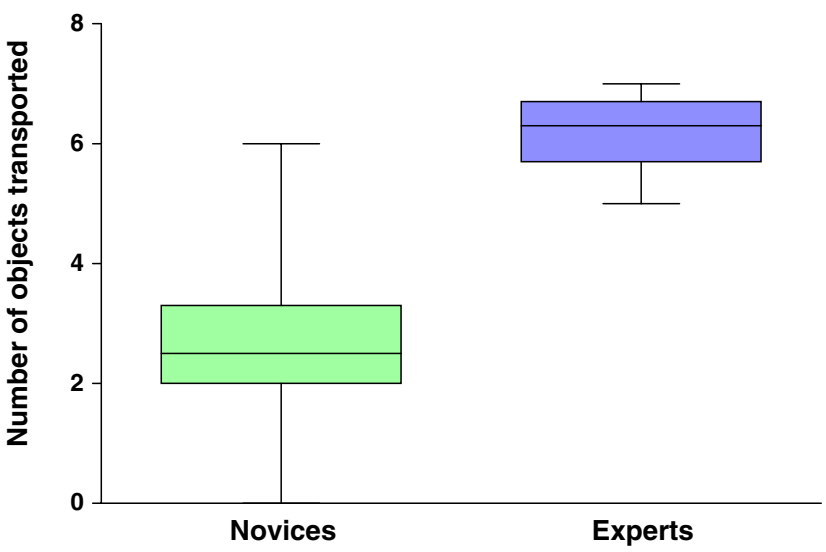

Study 2 ( $n=283)$, as the study was open to all those who wanted to participate, the level of participants could not be ascertained and they were described as novices $(n=241)$ or experts $(n=42)$ based on a self-reported questionnaire.

Participants received a full explanation and video-tape demonstrations of all exercises at the beginning of the studies but, although a tutor was standing next to them at 
Table 1 European Society for Gynaecological Endoscopy classification of gynaecological laparoscopic surgery

\begin{tabular}{l} 
Classification \\
\hline First level: basic level \\
- Diagnostic laparoscopy \\
- Tubal sterilisation \\
- Cyst aspiration \\
- Biopsy \\
Second level: intermediate level \\
- Salpingotomy \\
- Salpingectomy \\
- Oophorectomy \\
- Ovarian cystectomy \\
- Adhesiolysis \\
- Treatment of mild-moderate endometriosis \\
Third level: advance level \\
- Hysterectomy \\
- Myomectomy \\
- Extensive adhesiolysis \\
- Treatment of severe endometriosis \\
- Treatment of urinary incontinence \\
- Treatment of bladder or bowel injuries \\
Fourth level: special procedures \\
- Treatment of pelvic floor disorders \\
- Oncology (lymphadenectomy, radical hysterectomy, \\
- axiloscopy) \\
- Preatment of recto-vaginal nodules \\
\hline
\end{tabular}

each working station, no further instructions were given during the performance of the exercises.

Each repetition of the exercises demanded $100 \%$ efficacy (i.e. the repetition was considered complete and valid only after successful performance), allowing the measurement of one parameter only (e.g. time) and assuming that, with some limitations, errors and economy of movement would be reflected in the main parameter.

In Study 1 the feasibility of the LASTT model was assessed. In addition, laparoscopic skills were measured throughout 20 repetitions for E1 and 30 repetitions for E2 and $\mathrm{E} 3$, which were performed in chronological rather than in randomised order (i.e. E1, E2 and then E3), allowing evaluation of the learning curves and of the construct validity of the exercises. The training sessions per participant per day were limited to $1.5 \mathrm{~h}$, so that the results would be optimised (unpublished data). Intra-group and intergroup differences at the beginning and at the end of the study were evaluated with the non-parametric Wilcoxon signed rank test and the Mann-Whitney test (continuous variables without Gaussian distribution), for paired and unpaired comparisons, respectively. Median (interquartile range) values are presented in both text and figures.

In Study 2 large-scale testing of E1 $(n=283)$, E2 $(n=$ $202)$ and E3 $(n=202)$ was carried out to confirm the construct validity of the model and to evaluate the discriminatory value of ESGE classification. Participants performed three consecutive repetitions of the exercises. The individual average values of the triplicate observations were used for statistical analysis. Inter-group differences were evaluated with the non-parametric Mann-Whitney test (continuous variables without Gaussian distribution). Median (interquartile range) values are presented in both text and figures, together with the minimum and maximum values in the figures.

All statistical comparisons were performed with GraphPad Prism software, and two- tailed $P$ values $<0.05$ were considered significant.

\section{Results}

Study 1

Participants' demographic characteristics (i.e. age, gender, training status and $\mathrm{DH}$ ) are reported in Table 2.

In E1 (Fig. 2b), the time required for participants to identify the targets decreased from $266(209-440)$ s to 77 $(61-94) \mathrm{s}$ for novices $(P=0.0001)$ and from $103(75-140) \mathrm{s}$ to $50(40-54) \mathrm{s}$ for experts $(P=\mathrm{NS})$. Novices required longer time than experts at the beginning $(P=0.002)$ and at the end $(P=0.003)$ of the study.

In E2 (Fig. 3b), the number of objects transported increased from $2(1-3)$ to $9.5(6.5-11)$ for novices $(P=$ $0.0001)$ and from $7.5(5.5-9.5)$ to $12(10-12)$ for experts $(P=0.004)$. Novices transported fewer objects than experts at the beginning $(P<0.0001)$ and at the end $(P=0.01)$ of the study.

In E3 (Fig. 4b), the time required for individuals to transport the objects decreased from 319 (291-466) s to 98 $(85-117) \mathrm{s}$ for novices $(P=0.0001)$ and from $72(54-97) \mathrm{s}$ to $40(38-48) \mathrm{s}$ for experts $(P=0.002)$. Novices required longer time than experts at the beginning $(P<0.0001)$ and at the end $(P<0.0001)$ of the study.

\section{Study 2}

Participants' demographic characteristics (i.e. age, gender, training status and $\mathrm{DH}$ ) are reported in Table 3.

In E1 (Fig. 2c), the time required for participants to identify the targets was $188(144-292)$ s for novices and only $110(78-145) \mathrm{s}$ for experts $(P<0.0001)$.

In E2 (Fig. 3c), the numbers of objects transported were $2.3(1.3-3.7)$ for novices and $6.3(5.5-7.3)$ for experts $(P<$ $0.0001)$.

In E3 (Fig. 4c), the numbers of objects transported were $2.5(2.0-3.3)$ for novices and $6.3(5.7-6.7)$ for experts $(P<$ $0.0001)$. 
Table 2 Demographic characteristics of participants in Study 1 $(n=24)$

\begin{tabular}{lll}
\hline Characteristic & $\begin{array}{l}\text { Novices } \\
(n=14)\end{array}$ & $\begin{array}{l}\text { Experts } \\
(n=10)\end{array}$ \\
\hline $\begin{array}{l}\text { Age (median and range) in years } \\
\text { Gender }\end{array}$ & $20(18-55)$ & $45(35-60)$ \\
- Male & $8(57 \%)$ & $6(60 \%)$ \\
- Female & $6(43 \%)$ & $4(40 \%)$ \\
$\begin{array}{l}\text { Training status } \\
\text { - Student }\end{array}$ & $10(71 \%)$ & $0(0 \%)$ \\
- Resident in OB\&GYN & $0(0 \%)$ & $0(0 \%)$ \\
- Specialist in OB\&GYN & $4(29 \%)$ & $10(100 \%)$ \\
$\begin{array}{l}\text { Dominant hand } \\
\text { - Right } \\
\text { - Left }\end{array}$ & $12(86 \%)$ & $9(90 \%)$ \\
\hline
\end{tabular}

\section{Discussion}

Training in gynaecological laparoscopic techniques varies and is inadequately structured worldwide. It is a matter of concern that the standards that a future laparoscopist must meet in order to operate, either independently or under supervision, have not been adequately established. Although the basic knowledge and skills required are identical for all medical specialties that use, or might use, laparoscopic procedures, the initial training remains restricted to each specific discipline and, if at all, is structured on a departmental basis.

In Europe, the implementation of laparoscopy in daily practice varies largely according to the country, and most universities, and their teaching hospitals, do not offer residents a structured in-house training programme to acquire LPS prior to their training in the operating room. On the contrary, specific courses to improve laparoscopic skills are provided at specialised centres. However, due to the lack of standardisation, these centres follow different programmes with ambiguous objectives (only exposure vs full acquisition of the theoretical knowledge and practical familiarity with a specific technique) and under-documented results (e.g. hours of training and number of procedures required to reach proficiency). Furthermore, most of these programmes are not scientifically validated, do not address the specific training required for the acquisition of LPS, and do not take into consideration individuals' learning patterns.

In the USA, the Society of American Gastrointestinal and Endoscopic Surgeons (SAGES) has identified the same problem and has developed a programme called Fundamentals of Laparoscopic Surgery (FLS) aimed at the evaluation and training of individual surgeons [49-55].

In an attempt to counteract the diversity in strategies and regulations for training in laparoscopy among different
European countries, we have focussed on LPS only and aimed to develop a standardised, objective, simple and reproducible method for training and evaluation of these skills. We were fully aware of the advantages that virtual reality models offer for objectively tracking the learning process. However, we developed a simple inanimate and relatively cheap model to be used as an insert in existing trainer boxes. This would allow the system to be implemented anywhere (i.e. not only at specialised centres), not only by gynaecologists but also by all those who have the potential to carry out laparoscopic procedures (e.g. general surgeons, urologists).

Then, a series of simple and short exercises, resembling specific tasks required for laparoscopic surgery, were designed for this model. The strategy of using simple and short exercises allowed the assessment of specific skills (simple) and many repetitions (short) with the obvious benefit of allowing the evaluation of an individual's learning curve. So that only one parameter in each exercise (e.g. time) is able to be measured, $100 \%$ efficacy was demanded for each repetition (i.e. the repetition was considered to be complete only after the successful performance of the exercise), assuming with some limitations that any mistake would be reflected in the main parameter. Indeed, since errors and economy of movement were not specifically recorded, some information was obviously lost. In contrast with more complex scoring systems, such as the objective structured assessment of technical skills (OSATS) [56, 57], the system used in this study has the advantage of being objective, tutor independent and useful for self-assessment. We are aware that recording errors and economy of movement might detect participants' limitations, and that adequate tutoring might enhance the learning process. Therefore, these factors could be addressed in further studies.

Our data demonstrate that a simple inanimate model is feasible for both testing and training laparoscopic skills. A

Table 3 Demographic characteristics of participants in Study 2 $(n=283)$

\begin{tabular}{lll}
\hline Characteristic & $\begin{array}{l}\text { Novices } \\
(n=241)\end{array}$ & $\begin{array}{l}\text { Experts } \\
(n=42)\end{array}$ \\
\hline $\begin{array}{l}\text { Age (median and range) in years } \\
\text { Gender }\end{array}$ & $34(25-66)$ & $37(28-60)$ \\
- Male & $117(49 \%)$ & $22(52 \%)$ \\
- Female & $124(51 \%)$ & $20(48 \%)$ \\
$\begin{array}{l}\text { Training status } \\
\text { - Student }\end{array}$ & $0(0 \%)$ & $0(0 \%)$ \\
- Resident in OB\&GYN & $116(48 \%)$ & $0(0 \%)$ \\
- Specialist in OB\&GYN & $125(52 \%)$ & $42(100 \%)$ \\
Dominant hand & $225(93 \%)$ & $38(90 \%)$ \\
- Right & $16(7 \%)$ & $4(10 \%)$ \\
- Left &
\end{tabular}


clear learning curve was observed in Study 1 for both novices and experts, suggesting that participants reached a plateau in the last repetitions of each exercise. Since the exercises had been performed in chronological order (i.e. first the simplest and easiest and then the more complex and difficult), it is important to stress that the results observed in E2 and E3 had been influenced by the skills already acquired in the previous exercise. The data also indicate that systematic repetition of simple tasks, even without any tutor's feedback (e.g. instructions, corrections), already has a major impact on the learning process, which, as already stated, could be enhanced by closer tutoring.

Interestingly, in contrast with the exponential learning curves observed in E1 and E3, the shape of the E2 learning curve was linear. This might be related to the type of outcome parameters used (i.e. time for E1 and E3, and number for E2), indicating the importance of this variable when one is evaluating learning curves. Detailed evaluation of the learning curves (e.g. slope, shape and number of procedures required to reach the plateau) should be addressed in further studies specifically designed for that purpose.

In addition to the learning curves, both Study 1 and Study 2 demonstrated that experts had better skills than novices, proving the construct validity of the model. However, we should be cautious when interpreting this conclusion for Study 2 for two reasons. Firstly, the level of experience of participants was determined from a selfreporting questionnaire, which we were obviously unable to validate due to the sample size and the system used for recruiting participants. Secondly, the different levels of classification used (i.e. ESGE) overlap with levels of other classifications [e.g. European Society for Human Reproduction and Embryology (ESHRE) [58], Advancing Minimally Invasive Gynecology Worldwide, former The American Association of Gynecologic Laparoscopists (AAGL)], which is an unavoidable limitation due to the lack of a standardised universal system to classify gynaecological laparoscopic surgery [59]. To counteract this limitation we were very strict in our cut-off level. Indeed, we categorised as novices only those with no experience at all or those who had performed basic procedures only (i.e. diagnostic laparoscopy, tubal sterilisation, biopsy and/ or cyst puncture), regardless of the number of procedures already performed. In contrast, we categorised as experts those who had performed at least 30 procedures at a more advanced level, taking into account the fact that the number of cases needed to reach proficiency for some laparoscopic procedures varies between 15 and 30 [1-6].

Since the final aim of a training system is to assess the competency of the trainee, the performance on the model should predict, or at least correlate with, an individual's performance in the operating room. Our study was not designed to address this question, and we obviously cannot postulate yet on the predictive or concurrent validity of the model, which should be addressed in further studies. However, the face and content validity of the model is currently being evaluated, with promising preliminary results (unpublished data).

In summary, our study demonstrated that a simple inanimate model, with proven construct validity, may prove to be an excellent tool for testing and training LPS. The concept of testing and training someone's LPS before their classical training in the operating room can be compared with someone who wants to learn how to play golf. After an introduction to the basic technique, one has to train on the training turf and only after passing the skill test is a permit to enter the golf course given so one can learn to play the game properly. The LASTT model seems a cost-effective tool (i.e. it is an insert that can be used in any trainer box; the cost of the prototypes is less than $€ 100$; it is tutor independent) for providing an in-house programme for continuous training and evaluation of LPS in all surgical disciplines in which laparoscopic procedures are, or might be, performed.

Acknowledgements The studies were possible thanks to a scientific grant from the European Academy of Gynaecological Surgery. We would like to acknowledge all the staff of the Academy and, in particular, Dr. Y. Van Belle for the enormous organisational help in the realisation of the different workshops.

We acknowledge the Centre for Surgical Technologies of the Katholieke Universiteit Leuven (Leuven, Belgium), especially Prof. J. Deprest, A. Lissens and I. Laermans, and the ENDOVISION European School of Endoscopy Villach (Villach, Austria), especially Dr. G. Rauter and Dr. K. Oberwinker for their input and constructive support.

We also acknowledge the organisers of the different congresses who provided us with the platform for performing large-scale evaluation: Prof. S. Gordts (Leuven Institute for Fertility and Embryology), Prof. Z. Novak and Prof. C. Benedetto (European Congress on Obstetrics and Gynaecology), Prof. A. Ginés (Paraguayan Society of Obstetrics and Gynaecology), Prof. J.L.S. Carvalho (Portuguese Society of Reproductive Medicine) and Prof. A. Wattiez (Institut de Recherche contre les Cancers de l'Appareil Digestif/ European Institution of TeleSurgery).

We thank the Karl Storz Company (Tutlingen, Germany) for their support of the European Academy and the efforts made to provide us with the necessary material at the different locations.

The studies comply with the current laws of the country in which they were performed.

\section{References}

1. Aggarwal R, Tully A, Grantcharov T, Larsen CR, Miskry T, Farthing A, Darzi A (2006) Virtual reality simulation training can improve technical skills during laparoscopic salpingectomy for ectopic pregnancy. BJOG 113:1382-1387

2. Ascher-Walsh CJ, Capes T (2007) An evaluation of the resident learning curve in performing laparoscopic supracervical hysterectomies as compared with patient outcome: five-year experience. $\mathrm{J}$ Minim Invasive Gynecol 14:719-723 
3. Fleisch MC, Newton J, Steinmetz I, Whitehair J, Hallum A, Hatch KD (2007) Learning and teaching advanced laparoscopic procedures: do alternating trainees impair a laparoscopic surgeon's learning curve? J Minim Invasive Gynecol 14:293-299

4. Simons AJ, Anthone GJ, Ortega AE, Franklin M, Fleshman J, Geis WP, Beart RW Jr (1995) Laparoscopic-assisted colectomy learning curve. Dis Colon Rectum 38:600-603

5. Park JS, Kang SB, Kim SW, Cheon GN (2007) Economics and the laparoscopic surgery learning curve: comparison with open surgery for rectosigmoid cancer. World J Surg 31:1827-1834

6. Ghomi A, Littman P, Prasad A, Einarsson JI (2007) Assessing the learning curve for laparoscopic supracervical hysterectomy. JSLS 11:190-194

7. Teh SH, Hunter JG, Sheppard BC (2007) A suitable animal model for laparoscopic hepatic resection training. Surg Endosc 21:17381744

8. van Velthoven RF, Hoffmann P (2006) Methods for laparoscopic training using animal models. Curr Urol Rep 7:114-119

9. Heinrich M, Tillo N, Kirlum HJ, Till H (2006) Comparison of different training models for laparoscopic surgery in neonates and small infants. Surg Endosc 20:641-644

10. Kirlum HJ, Heinrich M, Tillo N, Till H (2005) Advanced paediatric laparoscopic surgery: repetitive training in a rabbit model provides superior skills for live operations. Eur J Pediatr Surg 15:149-152

11. Kirlum HJ, Heinrich M, Till H (2005) The rabbit model serves as a valuable operative experience and helps to establish new techniques for abdominal and thoracic endosurgery. Pediatr Surg Int 21:91-93

12. Machado MA, Galvao FH, Pompeu E, Ribeiro C, Bacchella T, Machado MC (2004) A canine model of laparoscopic segmental liver resection. J Laparoendosc Adv Surg Tech A 14:325-328

13. Molinas CR, Binda MM, Mailova K, Koninckx PR (2004) The rabbit nephrectomy model for training in laparoscopic surgery. Hum Reprod 19:185-190

14. Molinas CR, Cabral CR, Koninckx PR (1999) Effect of the diameter of the endoscope and of surgeon training on the duration and quality of laparoscopic surgery in a rabbit model. J Am Assoc Gynecol Laparosc 6:447-452

15. Menezes Ettinger JE, Santos-Filho PV, Oliveira PD, Azaro E, Mello CA, do Amaral PC, Fahel E (2006) Laparoscopic gastric banding in the rat model as a means of videolaparoscopic training. Obes Surg 16:903-907

16. Katz R, Hoznek A, Antiphon P, van Velthoven R, Delmas V, Abbou CC (2003) Cadaveric versus porcine models in urological laparoscopic training. Urol Int 71:310-315

17. Undre S, Darzi A (2007) Laparoscopy simulators. J Endourol 21:274-279

18. McDougall EM (2007) Validation of surgical simulators. J Endourol 21:244-247

19. Bruynzeel H, de Bruin AF, Bonjer HJ, Lange JF, Hop WC, Ayodeji ID, Kazemier G (2007) Desktop simulator: key to universal training? Surg Endosc 21:1637-1640

20. Katz R (2006) Methods of training using pelvic trainers. Curr Urol Rep 7:100-106

21. Munz Y, Kumar BD, Moorthy K, Bann S, Darzi A (2004) Laparoscopic virtual reality and box trainers: is one superior to the other? Surg Endosc 18:485-494

22. Munz Y, Almoudaris AM, Moorthy K, Dosis A, Liddle AD, Darzi AW (2007) Curriculum-based solo virtual reality training for laparoscopic intracorporeal knot tying: objective assessment of the transfer of skill from virtual reality to reality. Am J Surg 193:774-783

23. Cosman PH, Hugh TJ, Shearer CJ, Merrett ND, Biankin AV, Cartmill JA (2007) Skills acquired on virtual reality laparoscopic simulators transfer into the operating room in a blinded, randomised, controlled trial. Stud Health Technol Inform 125:76-81

24. Botden SM, Buzink SN, Schijven MP, Jakimowicz JJ (2007) Augmented versus virtual reality laparoscopic simulation: what is the difference? A comparison of the ProMIS augmented reality laparoscopic simulator versus LapSim virtual reality laparoscopic simulator. World J Surg 31:764-772

25. van Dongen KW, Tournoij E, van der Zee DC, Schijven MP, Broeders IAMJ (2007) Construct validity of the LapSim: can the LapSim virtual reality simulator distinguish between novices and experts? Surg Endosc 21:1413-1417

26. Rosenthal R, Gantert WA, Scheidegger D, Oertli D (2006) Can skills assessment on a virtual reality trainer predict a surgical trainee's talent in laparoscopic surgery? Surg Endosc 20:1286-1290

27. Larsen CR, Grantcharov T, Aggarwal R, Tully A, Sorensen JL, Dalsgaard T, Ottesen B (2006) Objective assessment of gynecologic laparoscopic skills using the LapSimGyn virtual reality simulator. Surg Endosc 20:1460-1466

28. Schijven MP, Jakimowicz JJ (2003) Introducing the Xitact LS500 laparoscopy simulator: toward a revolution in surgical education. Surg Technol Int 11:32-36

29. Maithel S, Sierra R, Korndorffer J, Neumann P, Dawson S, Callery M, Jones D, Scott D (2006) Construct and face validity of MIST-VR, Endotower, and CELTS: are we ready for skills assessment using simulators? Surg Endosc 20:104-112

30. Andreatta PB, Woodrum DT, Birkmeyer JD, Yellamanchilli RK, Doherty GM, Gauger PG, Minter RM (2006) Laparoscopic skills are improved with LapMentor training: results of a randomized, double-blinded study. Ann Surg 243:854-860

31. Fraser SA, Klassen DR, Feldman LS, Ghitulescu GA, Stanbridge D, Fried GM (2003) Evaluating laparoscopic skills: setting the pass/fail score for the MISTELS system. Surg Endosc 17:964-967

32. Korndorffer JR Jr, Hayes DJ, Dunne JB, Sierra R, Touchard CL, Markert RJ, Scott DJ (2005) Development and transferability of a cost-effective laparoscopic camera navigation simulator. Surg Endosc 19:161-167

33. Korndorffer JR Jr, Scott DJ, Sierra R, Brunner WC, Dunne JB, Slakey DP, Townsend MC, Hewitt RL (2005) Developing and testing competency levels for laparoscopic skills training. Arch Surg 140:80-84

34. Stefanidis D, Haluck R, Pham T, Dunne JB, Reinke T, Markley S, Korndorffer JR Jr, Arellano P, Jones DB, Scott DJ (2007) Construct and face validity and task workload for laparoscopic camera navigation: virtual reality versus videotrainer systems at the SAGES Learning Center. Surg Endosc 21:1158-1164

35. Derossis AM, Fried GM, Abrahamowicz M, Sigman HH, Barkun JS, Meakins JL (1998) Development of a model for training and evaluation of laparoscopic skills. Am J Surg 175:482-487

36. Fraser SA, Feldman LS, Stanbridge D, Fried GM (2005) Characterizing the learning curve for a basic laparoscopic drill. Surg Endosc 19:1572-1578

37. Gor M, McCloy R, Stone R, Smith A (2003) Virtual reality laparoscopic simulator for assessment in gynaecology. BJOG 110:181-187

38. Scott DJ, Young WN, Tesfay ST, Frawley WH, Rege RV, Jones DB (2001) Laparoscopic skills training. Am J Surg 182:137-142

39. Vossen C, Van Ballaer P, Shaw RW, Koninckx PR (1997) Effect of training on endoscopic intracorporeal knot tying. Hum Reprod $12: 2658-2663$

40. Korndorffer JR Jr, Stefanidis D, Scott DJ (2006) Laparoscopic skills laboratories: current assessment and a call for resident training standards. Am J Surg 191:17-22

41. Korndorffer JR Jr, Dunne JB, Sierra R, Stefanidis D, Touchard CL, Scott DJ (2005) Simulator training for laparoscopic suturing using performance goals translates to the operating room. J Am Coll Surg 201:23-29

42. Stefanidis D, Korndorffer JR Jr, Heniford BT, Scott DJ (2007) Limited feedback and video tutorials optimize learning and resource utilization during laparoscopic simulator training. Surgery 142:202-206 
43. Stefanidis D, Korndorffer JR Jr, Markley S, Sierra R, Heniford BT, Scott DJ (2007) Closing the gap in operative performance between novices and experts: does harder mean better for laparoscopic simulator training? J Am Coll Surg 205:307-313

44. Stefanidis D, Scerbo MW, Korndorffer JR Jr, Scott DJ (2007) Redefining simulator proficiency using automaticity theory. Am J Surg 193:502-506

45. Stefanidis D, Korndorffer JR Jr, Black FW, Dunne JB, Sierra R, Touchard CL, Rice DA, Markert RJ, Kastl PR, Scott DJ (2006) Psychomotor testing predicts rate of skill acquisition for proficiency-based laparoscopic skills training. Surgery 140:252-262

46. Stefanidis D, Korndorffer JR Jr, Markley S, Sierra R, Scott DJ (2006) Proficiency maintenance: impact of ongoing simulator training on laparoscopic skill retention. J Am Coll Surg 202:599603

47. Stefanidis D, Sierra R, Korndorffer JR Jr, Dunne JB, Markley S, Touchard CL, Scott DJ (2006) Intensive continuing medical education course training on simulators results in proficiency for laparoscopic suturing. Am J Surg 191:23-27

48. Stefanidis D, Korndorffer JR Jr, Sierra R, Touchard C, Dunne JB, Scott DJ (2005) Skill retention following proficiency-based laparoscopic simulator training. Surgery 138:165-170

49. Fried GM, Feldman LS, Vassiliou MC, Fraser SA, Stanbridge D, Ghitulescu G, Andrew CG (2004) Proving the value of simulation in laparoscopic surgery. Ann Surg 240:518-525

50. Ritter EM, Kindelan TW, Michael C, Pimentel EA, Bowyer MW (2007) Concurrent validity of augmented reality metrics applied to the fundamentals of laparoscopic surgery (FLS). Surg Endosc 21:1441-1445
51. Ritter EM, Scott DJ (2007) Design of a proficiency-based skills training curriculum for the fundamentals of laparoscopic surgery. Surg Innov 14:107-112

52. McCluney AL, Vassiliou MC, Kaneva PA, Cao J, Stanbridge DD, Feldman LS, Fried GM (2007) FLS simulator performance predicts intraoperative laparoscopic skill. Surg Endosc 21:1991-1995

53. Swanstrom LL, Fried GM, Hoffman KI, Soper NJ (2006) Beta test results of a new system assessing competence in laparoscopic surgery. J Am Coll Surg 202:62-69

54. Scott DJ, Ritter EM, Tesfay ST, Pimentel EA, Nagji A, Fried GM (2008) Certification pass rate of $100 \%$ for fundamentals of laparoscopic surgery skills after proficiency-based training. Surg Endosc, DOI 10.1007/s004640089745

55. Fried GM (2008) FLS assessment of competency using simulated laparoscopic tasks. J Gastrointest Surg 12:210-212

56. Faulkner H, Regehr G, Martin J, Reznick R (1996) Validation of an objective structured assessment of technical skill for surgical residents. Acad Med 71:1363-1365

57. Martin JA, Regehr G, Reznick R, MacRae H, Murnaghan J, Hutchison C, Brown M (1997) Objective structured assessment of technical skill (OSATS) for surgical residents. Br J Surg 84:273-278

58. Chapron C, Devroey P, Dubuisson JB, Pouly JL, Vercellini P (1997) ESHRE guidelines for training, accreditation and monitoring in gynaecological endoscopy. European Society for Human Reproduction and Embryology. Committee of Special Interest Group on Reproductive Surgery. Hum Reprod 12:867-868

59. Campo R, Wattiez A, Wallwiener D, Molinas CR (2005) Training and education in endoscopic surgery: is there a future for endoscopy in OB\&GYN training? Gynecol Surg 2:57-65 